\title{
Silica-supported sulfonic acids as recyclable catalyst for esterification of levulinic acid with stoichiometric amounts of alcohols
}

\author{
Raimondo Maggi ${ }^{* 1}$, N. Raveendran Shiju ${ }^{*}$, Veronica Santacroce ${ }^{1,2}$, Giovanni Maestri ${ }^{1}$, \\ Franca Bigi ${ }^{1,3}$ and Gadi Rothenberg ${ }^{2}$
}

\author{
Full Research Paper \\ Address: \\ ${ }^{1}$ Clean Synthetic Methodology Group, Dipartimento di Chimica, \\ Università di Parma, Parco Area delle Scienze 17A, I-43124 Parma, \\ Italy, ${ }^{2}$ Van 't Hoff Institute for Molecular Sciences, University of \\ Amsterdam, Science Park 904, $1098 \mathrm{XH}$, Amsterdam, The \\ Netherlands. Tel: $+31-20-5256515$ and ${ }^{3}$ Istituto IMEM-CNR, Parco \\ Area delle Scienze 37/A, I-43124 Parma, Italy \\ Email: \\ Raimondo Maggi - raimondo.maggi@unipr.it; N. Raveendran Shiju* - \\ n.r.shiju@uva.nl \\ * Corresponding author \\ Keywords: \\ esterification; heterogeneous catalysis; renewable feedstocks; \\ supported organic catalysts; sustainable chemistry \\ Beilstein J. Org. Chem. 2016, 12, 2173-2180. \\ doi:10.3762/bjoc. 12.207 \\ Received: 27 July 2016 \\ Accepted: 22 September 2016 \\ Published: 12 October 2016 \\ This article is part of the Thematic Series "Green chemistry". \\ Guest Editor: L. Vaccaro \\ (C) 2016 Maggi et al.; licensee Beilstein-Institut. \\ License and terms: see end of document.
}

\begin{abstract}
Converting biomass into value-added chemicals holds the key to sustainable long-term carbon resource management. In this context, levulinic acid, which is easily obtained from cellulose, is valuable since it can be transformed into a variety of industrially relevant fine chemicals. Here we present a simple protocol for the selective esterification of levulinic acid using solid acid catalysts. Silica supported sulfonic acid catalysts operate under mild conditions and give good conversion and selectivity with stoichiometric amounts of alcohols. The sulfonic acid groups are tethered to the support using organic tethers. These tethers may help in preventing the deactivation of the active sites in the presence of water.
\end{abstract}

\section{Introduction}

Vegetal biomass is mankind's only source of renewable carbon on a human timescale. It is abundantly available, with the potential of replacing fossil-based carbon on a scale sufficient for covering the worldwide demand for non-fuel chemicals [1-4]. Currently, the main research thrust is directed at lignocellulose, the most abundant fraction of biomass. The mass com- 
position of lignocellulose could be roughly represented by a $5 / 3 / 2$ ratio of cellulose, hemicellulose and lignin, respectively. All of these polymers are the subject of many studies [5-11].

Levulinic acid (LA) is one of the most important platform chemicals as it is a versatile building block for a variety of value-added agrochemicals, fine chemicals and pharmaceutical intermediates [12,13] (Scheme 1, bottom). Moreover, it can be obtained from cellulose with relative ease and high selectivity (see Scheme 1, top) [14].

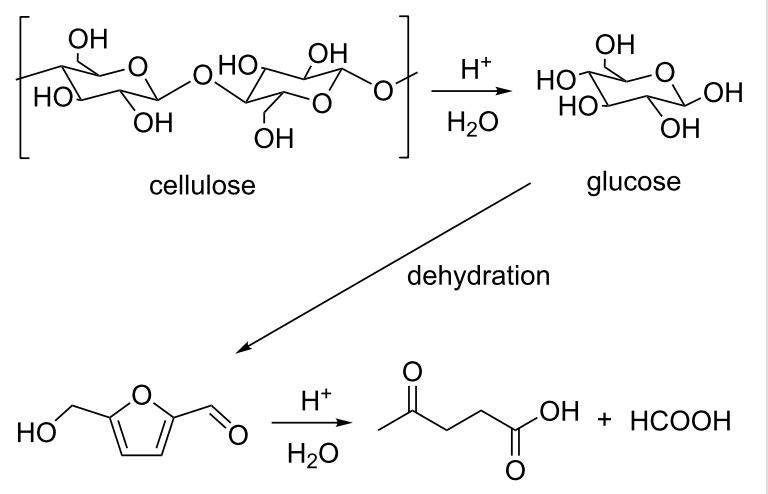

HMF

levulinic acid

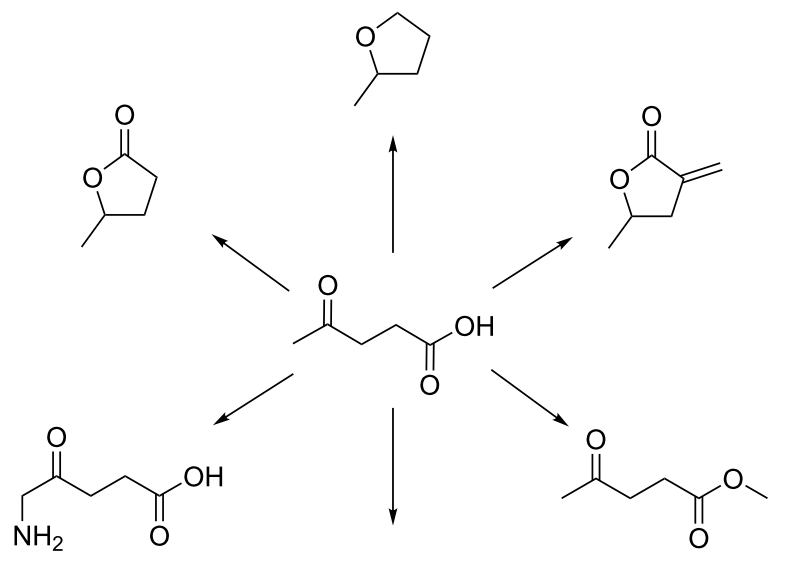<smiles>CC(O)CCCO</smiles>

Scheme 1: Synthesis of levulinic acid from ligno-cellulosic feedstocks and its principal uses to access fine chemicals.

Levulinic acid esters are of particular interest for the chemical industry $[12,13]$. Their main current market is represented by the formulation of flavours and fragrances [15], although the scale of these preparations did not boosted demand yet. However, the seek to develop more eco-compatible solvents might grant to levulinates a novel route of application. By tailoring their physicochemical properties they could become complementary to common esters and other solvents, which might be more harmful for both humans and the environment [16]. It should be also noted that ethyl levulinate could shrink the emission of nitrogen oxides from exhausts of diesel engines when used as additive $[17,18]$.

Due to their importance, new strategies have been developed for the production of levulinic esters [19-22]. Homogeneous Brønsted acids could catalyse the esterification of levulinic acid in the presence of alcohols and reports on this reactivity date back to the nineties [23]. Although this route could ensure high chemical yields, it still presents a series of drawbacks. In particular, issues with catalyst recycling and product separation limits the environmental viability of this strategy. As a result, it remains of high interest to develop alternatives to trigger this reaction, which are more sustainable, for instance through the design of suitable and recyclable solid acid catalysts. In the literature, methods that use solid heteropolyacids, such as ammonium or mixed ammonium and silver-doped phosphotungstic acid, sulfated metal oxides (such as sulfated titania, sulfated zirconia), zeolites and hydrotalcites have been reported [24-30]. These solid catalysts share several advantages, including high activity and an easy recovery, which might provide a real basis for future application in commercial processes. Nevertheless, they require high temperatures (usually above $100{ }^{\circ} \mathrm{C}$ ) and long reaction times [24-30]. Furthermore, they often share another common pitfall, namely the use of large molar excess of alcohol, either for practical convenience [31] or to minimise ester hydrolysis. As meaningful examples, it has been recently reported that acid ZSM-5 zeolites, with encapsulated maghemite particles to allow magnetic catalyst recover, could be used to directly convert furfuryl alchol into an alkyl levulinate upon warming at $130{ }^{\circ} \mathrm{C}$ for 8 hours in the presence of a large excess of alchol as solvent/reagent (100 equiv) [32]. A1though the behaviour of many metal oxides has been investigated, reports featuring the activity of supported organic Brønsted acids are very few. In particular, Tejero reported that sulfonic acid supported on polymeric resins could catalyse the esterification of LA, providing conversions up to $94 \%$ upon warming at $80{ }^{\circ} \mathrm{C}$ for 8 hours in the presence of 3 equiv of $n$-butanol [33]. Melero described the synthesis of mesostructured silica frameworks featuring pending organosulfonic arms. The best catalyst provided quantitative conversion of LA upon warming of the reaction mixture at $130{ }^{\circ} \mathrm{C}$ for 2 hours in the presence of a fivefold molar excess of ethanol, used as solvent/reagent [34].

Here we present an alternative strategy in which a heterogeneous catalyst triggers the selective esterification of levulinic acid with a stoichiometric amount of alcohol. 
In the last years, many methods have been developed for the transformation of homogeneous catalysts into recyclable heterogeneous ones. To prevent leaching, a common strategy is tethering the active species with the support via covalent bonds [35]. This approach increases the stability of the catalyst itself compared to impregnation (Figure 1). Furthermore, the activity of the catalyst can be tuned through adoption of a suitable linker.

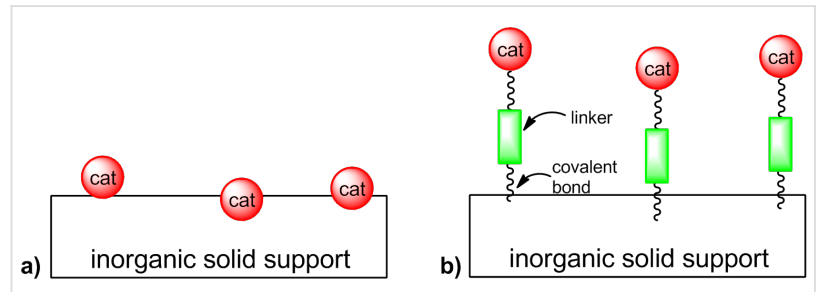

Figure 1: Anchoring methodologies: a) impregnation; b) covalent binding.

\section{Results and Discussion}

As part of our interest in acid catalysis [36-38], we prepared a set of solid materials for the esterification of levulinic acid. Upon preliminary screening, supported sulfonic acids seemed promising candidates. They were prepared following a reported procedure by the tethering method [39], which consists of the immobilisation of a functional moiety on an inorganic support via covalent bonds ensured by a suitable linker [35].

In preliminary experiments reactions were carried out with a five-fold molar excess of alcohol. We started from this ratio as in the literature we did not retrieve any catalytic method for the esterification of biomass-derived acids that operates with a lower molar excess of alcohol [24-34]. 1-Pentanol was selected as model substrate in order to work over an ample range of operating temperatures. Thus, in a typical experiment, $10 \mathrm{mmol}$ of levulinic acid were stirred at $100{ }^{\circ} \mathrm{C}$ in a sealed tube for $2 \mathrm{~h}$ under air in the presence of the amount of a solid catalyst necessary to have $1 \mathrm{~mol} \%$ of acid sites. The results are reported in Table 1 .

All of the prepared silica-supported sulfonic acids showed very good catalytic activity for the esterification of levulinic acid (Table 1, entries 1-4). Materials with an arylsulfonic moiety were initially investigated (Table 1, entries 1 and 2). They present a comparable loading of Brønsted sites (0.73 and $0.65 \mathrm{mmol} / \mathrm{g}$ respectively) and ensured conversion of 1 above $90 \%$ within two hours (94 and 92\%). The catalyst without any alkyl tether was more selective, ultimately delivering the desired product 3a in $90 \%$ yield. Silica-supported propyl sulfonic acid provided slightly better results (Table 1, entries 3 and 4). The material presented a lower density of Brønsted sites $(0.51 \mathrm{mmol} / \mathrm{g})$, but delivered almost complete conversion of $\mathbf{1}$ within $2 \mathrm{~h}$ (>95\%), affording 3a in 93\% yield. We then repeated the experiment adding activated molecular sieve in the reaction flask (Table 1, entry 4) to check whether water coproduced by the reaction could cause any harm. The outcome paralleled the standard procedure, conversion and yield being $96 \%$ and $94 \%$, respectively. This result shows that the presence of water is tolerated by the catalytic system, which in turn did not easily trigger the hydrolysis of levulinates under these conditions.

Table 1: Screening of different solid acids in the esterification reaction of levulinic acid with 1-pentanol.

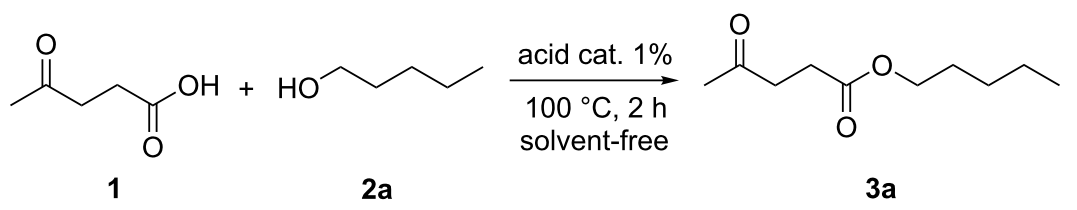

\begin{tabular}{|c|c|c|c|c|c|}
\hline Entry & Sulfonated catalyst & Catalyst acidity $(\mathrm{mmol} \mathrm{H} / \mathrm{g})$ & Conversion of $1(\%)$ & Yield of $3 \mathbf{a}(\%)$ & Selectivity of $\mathbf{3 a}(\%)$ \\
\hline 1 & $\mathrm{SiO}_{2}-\left(\mathrm{CH}_{2}\right)_{3}-\mathrm{O}-\mathrm{C}_{6} \mathrm{H}_{4}-\mathrm{SO}_{3} \mathrm{H}$ & 0.73 & 94 & 84 & 89 \\
\hline 2 & $\mathrm{SiO}_{2}-\mathrm{C}_{6} \mathrm{H}_{4}-\mathrm{SO}_{3} \mathrm{H}$ & 0.65 & 92 & 90 & 98 \\
\hline 3 & $\mathrm{SiO}_{2}-\left(\mathrm{CH}_{2}\right)_{3}-\mathrm{SO}_{3} \mathrm{H}$ & 0.51 & 95 & 93 & 98 \\
\hline $4^{a}$ & $\mathrm{SiO}_{2}-\left(\mathrm{CH}_{2}\right)_{3}-\mathrm{SO}_{3} \mathrm{H}$ & 0.51 & 96 & 94 & 98 \\
\hline 5 & Amberlyst 15 & 4.70 & 52 & 31 & 60 \\
\hline 6 & Nafion $^{\circledR}$ & 0.80 & 72 & 68 & 94 \\
\hline 7 & Aquivion $^{\circledR}$ & 0.12 & 84 & 80 & 95 \\
\hline 8 & $\mathrm{H}_{2} \mathrm{SO}_{4}$ & & 57 & 55 & 96 \\
\hline
\end{tabular}

aWith the addition of $4 \AA$ molecular sieves. Values by GC upon calculation of response factors for $\mathbf{1}$ and $\mathbf{3 a}$ from pure samples over the concentration interval of the reaction; the selectivity has been calculated as the ration between yield of $\mathbf{3 a}$ and conversion of 1. 
Remarkably, the presence of water on the catalyst surface can inhibit the catalytic sites of inorganic materials instead [40]. Acidic and/or hydrophilic metal oxides and sulfates easily adsorb water on their surface, which is the coproduct of the esterification. This can severely reduce the activity of the catalyst. Considering our supported sulfonic acids, we speculate that their organic tethers could smooth the hydrophilic character of their Brønsted sites and thus prevent the deactivation due to water.

We then tested a selection of commercial catalysts (Table 1, entries 5-7). Despite encouraging literature precedents [22,33], Amberlyst 15 gave only $52 \%$ conversion of 1 within $2 \mathrm{~h}$ (Table 1, entry 5, 31\% yield). We then switched to perfluorinated resins. Nafion ${ }^{\circledR}$ and Aquivion ${ }^{\circledR}$ showed an interesting selectivity towards $\mathbf{3 a}$, but conversion of $\mathbf{1}$ proved once again below that observed with supported sulfonic acids $(72 \%$ and $84 \%$, respectively). Finally, a common homogeneous acid was used for comparison. The use of $1 \mathrm{~mol} \%$ of $\mathrm{H}_{2} \mathrm{SO}_{4}$ (Table 1 , entry 8 ) delivered $3 \mathbf{a}$ in $55 \%$ yield only. Furthermore, conversion of 1 remained stuck at $57 \%$ even prolonging the reaction time for up to $24 \mathrm{~h}$. This result shows that heterogeneous sulfonic acids outperform their homogeneous peer under these conditions.

Upon identification of silica-supported sulfonic acids as cheap and promising candidates for the selective esterification of LA, the reaction parameters were then optimized in order to maximise the environmental viability of the method. We thus tried to shelve the molar excess of the alcohol (Table 2).

Reactions were carried out at $100{ }^{\circ} \mathrm{C}$ and regularly monitored for $2 \mathrm{~h}$. To our delight, varying the amount of alcohol did not hamper neither conversion nor selectivity. Indeed, 3a was recovered in $93 \%$ yield using a two-fold molar excess of 2 (Table 2, entry 2). A comparable result was achieved with a stoichiometric amount of pentanol (Table 2, entry 3, 94\% yield). It is remarkable that even in this case the amount of water coproduced by the esterification did not cause any significant hydrolysis of the desired ester 3a. Furthermore, the almost complete conversion of $\mathbf{1}$ with a stoichiometric amount of $\mathbf{2 a}$ allows minimising the consumption of reagents and therefore the overall costs of the transformation. To the best of our knowledge, using stoichiometric amounts of alcohol has not been reported previously. In the present case, this can be possible as we could show that a relatively high concentration of water did not hinder the reaction. Catalysts more prone to deactivation might require a larger molar excess of alcohols to prevent waterpoisoning.

The reaction conditions were further optimized studying the effect of the temperature. So, a series of experiments were carried out using the sulfonated catalyst (1\%), an equimolecular amount of reagents under solvent free conditions, and varying the temperature between $50-100{ }^{\circ} \mathrm{C}$. Results are reported in Table 3 .

In all cases, the selectivity towards the esterification product $\mathbf{3 a}$ remained complete. A comparable yield of $\mathbf{3 a}$ was recovered reducing the temperature from 100 to $75^{\circ} \mathrm{C}$ (Table 3, entry 2, $93 \%$ ). By reducing the temperature to $50{ }^{\circ} \mathrm{C}$ (Table 3 , entry 3 ), longer reaction times became necessary. At $50{ }^{\circ} \mathrm{C}$, conversion peaked at $79 \%$ upon $7 \mathrm{~h}$ and no longer improved even by keeping the mixture for further $24 \mathrm{~h}$. Reasoning on the practical viability of the method, we therefore continued our study fixing the temperature at $75^{\circ} \mathrm{C}$. We then evaluated the amount of catalyst (Table 4).

Surprisingly, an increase of the catalyst amount to $5 \mathrm{~mol} \%$ resulted in lower selectivity towards $\mathbf{3 a}$, which has been retrieved in $85 \%$ yield together with traces of one unidentified byproduct (Table 4 , entry 1 ). On the other hand, reduction of the catalyst loading to $0.1 \mathrm{~mol} \%$ slows down the process, conversion being just $36 \%$ upon $2 \mathrm{~h}$ (Table 4 , entry 3 ). Further reduction to $0.01 \mathrm{~mol} \%$ confirmed this trend and delivered $3 \mathbf{a}$ in $14 \%$ yield (Table 4, entry 4). Even by prolonging the reac-

Table 2: Variation of the acid/alcohol ratio.

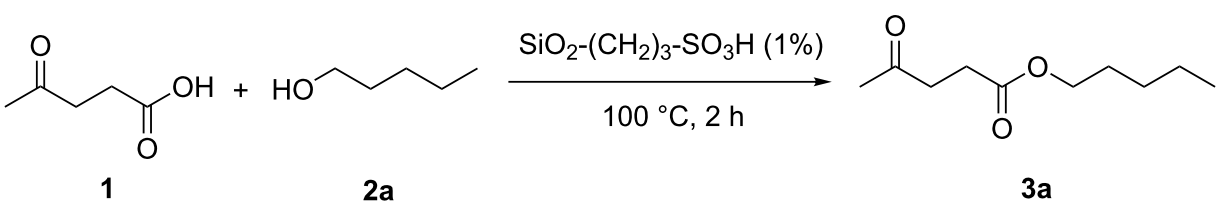

\begin{tabular}{ccccc}
\hline Entry & \multicolumn{2}{c}{ Acid:alcohol ratio } & Conversion of 1 (\%) & Yield of 3a (\%) \\
\hline 1 & $1: 5$ & 96 & 94 & 98 \\
2 & $1: 2$ & 95 & 93 & 98 \\
3 & $1: 1$ & 96 & 94 & 98
\end{tabular}


Table 3: Variation of the reaction temperature.

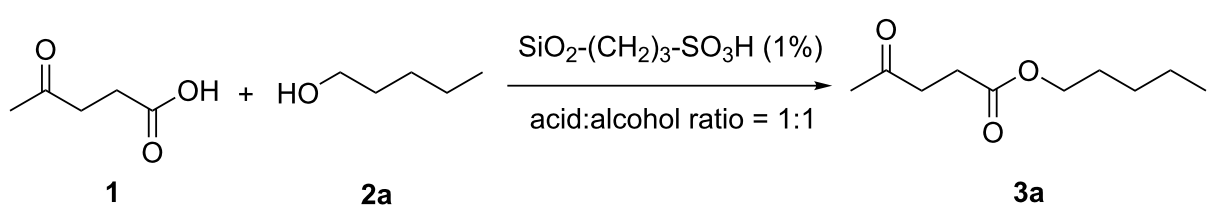

1 $\mathbf{2 a}$ $3 a$

\begin{tabular}{ccccc}
\hline Entry & Temperature $\left({ }^{\circ} \mathrm{C}\right)$ & Conversion of 1 (\%) & Yield of 3a (\%) & Selectivity of 3a (\%) \\
\hline 1 & 100 & 96 & 94 & 98 \\
2 & 75 & 95 & 93 & 98 \\
3 & 50 & 79 & 77 & 2 \\
\end{tabular}

Table 4: Effect of the amount of catalyst.

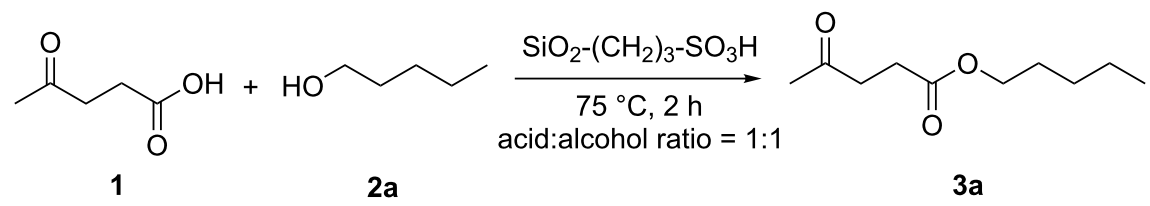

\begin{tabular}{ccccc}
\hline Entry & Catalyst amount (\%) & Conversion of 1 (\%) & Yield of 3a (\%) & Selectivity of 3a (\%) \\
\hline 1 & 5 & 95 & 85 & 93 \\
2 & 1 & 95 & 35 & 93 \\
3 & 0.1 & 36 & 14 & 93
\end{tabular}

tion time to $24 \mathrm{~h}$, conversion did not reach completion and the ester was isolated in 58 and $38 \%$ yield with 0.1 and $0.01 \mathrm{~mol} \%$ of catalyst, respectively. In any case, the selectivity remained almost complete ( $>98 \%$ by GC).

We then ensured that the catalyst acts as a heterogeneous species by performing a filtration test. In agreement with the hypothesis, we monitored no further conversion on the filtrate [41], proving that no leaching occurred. The recyclability of the catalyst was then evaluated. The catalyst was recovered by filtration, washed with ethyl acetate $(10 \mathrm{~mL})$, dried and reused for a further esterification. The results are shown in Figure 2.

The catalyst can be recovered and reused for 6 cycles at least, fully preserving its activity and selectivity. For instance, conversion of $\mathbf{1}$ and yield of $\mathbf{3 a}$ were 94 and $92 \%$, respectively, upon the fifth re-cycle.

Finally, with optimized conditions in our hands, we checked the scope of this catalytic methodology (Table 5).

As expected, the best performances were obtained with primary alcohols (Table 5, entries 1 and 2), which afforded the desired ester in 93 and $79 \%$ yield, respectively. Gratifyingly, the

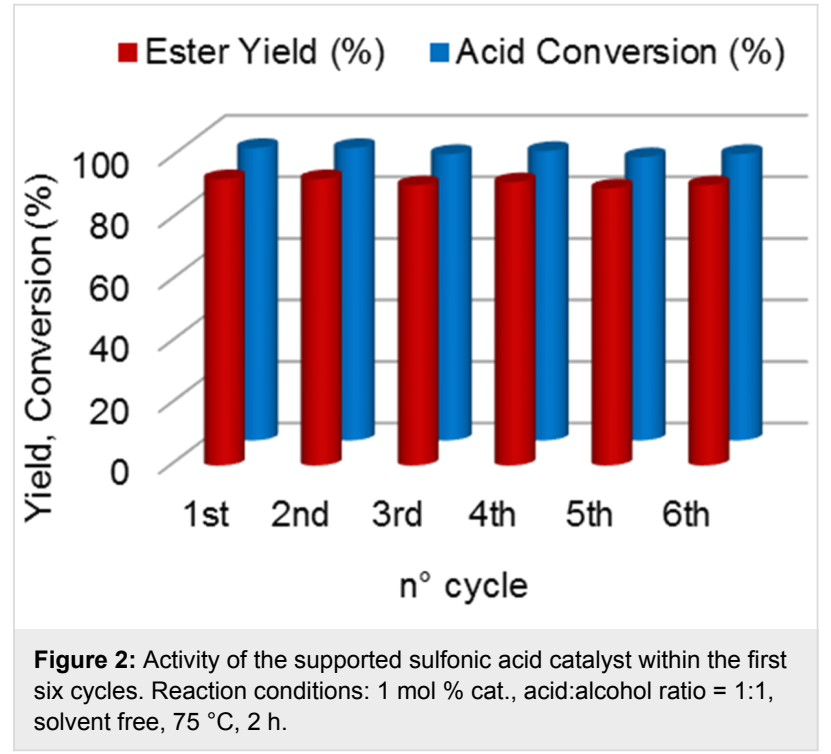

method could be extended to secondary alcohols as isopropanol and L-menthol. Despite their increased steric hindrance, very good results were obtained with a selectivity towards $3>99 \%$ (Table 5; entries 3 and 4, 59 and $76 \%$ yield). In particular, it is important to underline that a single diastereomer of product 3d was formed (Table 4, entry 4). This implies that the present 
Table 5: Esterification of levulinic acid with different alcohols.

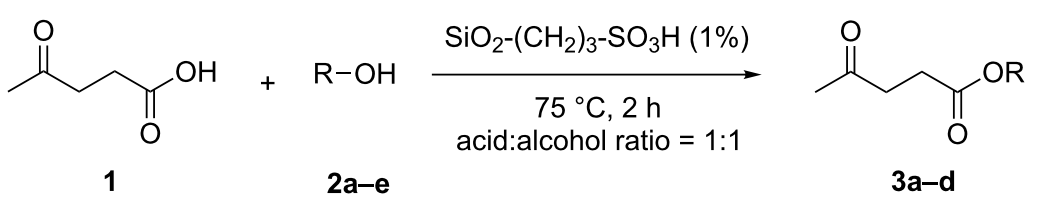

\begin{tabular}{|c|c|c|c|c|}
\hline Entry & Alcohol & Conversion of $1(\%)$ & Yield of $3(\%)^{a}$ & Selectivity of $3(\%)$ \\
\hline 1 & $2 a$ & 95 & 93 & 98 \\
\hline $2^{b}$ & 2b & 80 & 79 & 99 \\
\hline 3 & 2c & 60 & 59 & 98 \\
\hline 4 & $2 d$ & 77 & 76 & 99 \\
\hline $5^{c}$ & $2 e$ & 0 & 0 & - \\
\hline
\end{tabular}

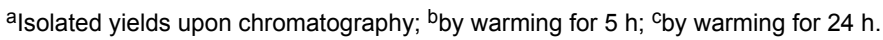

method, likely thanks to its mild conditions, allows to preserve chiral information present on substrates and could thus efficiently transfer it on the products.

On the other hand, no conversion of $\mathbf{1}$ was observed using tertiary alcohols, as witnessed by entry 5 . Probably, their steric hindrance quenches any reactivity.

\section{Conclusion}

Silica-supported sulfonic acids proved very active heterogeneous catalysts for the selective esterification of levulinic acid with stoichiometric amounts of primary alcohols. The esterification can be carried out under mild conditions $\left(75^{\circ} \mathrm{C}, 2 \mathrm{~h}\right)$ and provides good to excellent yields with various primary and secondary alcohols. The selectivity towards desired products remained complete in all cases. The coproduct of the reaction, namely water, did not hamper the efficiency of this solvent-free process.

The selected catalyst is cheap, can be easily prepared from commercial reagents and proved very robust. It is very active and selective, water-tolerant and recyclable. It represents therefore an interesting and complementary alternative to existing esterification catalysts. Together with the absence of solvents and of any molar excess of reagents, these features highlight the practical and environmental viability of this catalytic method.

\section{Experimental}

\section{Catalysts preparation}

$\mathbf{S i O}_{2}-\left(\mathrm{CH}_{2}\right)_{3}-\mathrm{SO}_{3} \mathbf{H}$ [35]: Amorphous silica (8.0 g) has been refluxed under stirring for $24 \mathrm{~h}$ with (3-mercaptopropyl)trimethoxysilane (MPTS) $(1.15 \mathrm{~mL} ; 6.1 \mathrm{mmol})$ in toluene $(120 \mathrm{~mL})$ and the resulting supported propylmercaptane has been oxidized to propanesulfonic acid by treatment with $30 \%$ aq $\mathrm{H}_{2} \mathrm{O}_{2}(100 \mathrm{~mL} ; 1 \mathrm{~mol})$ for $24 \mathrm{~h}$ under stirring at $\mathrm{rt}$, adding a few drops of concentrated sulfuric acid after $12 \mathrm{~h}$. Acidity has been measured via the titration method [35] $\left(0.51 \mathrm{mmol} \mathrm{H}^{+} / \mathrm{g}\right)$.

$\mathbf{S i O}_{2}-\mathbf{C}_{6} \mathbf{H}_{4}-\mathbf{S O}_{3} \mathbf{H}$ [35]: Amorphous silica (8.0 g) has been refluxed in toluene $(120 \mathrm{~mL})$ with phenyltriethoxysilane $(2.0 \mathrm{~mL}$, $8.3 \mathrm{mmol})$ under stirring for 24 hours. The resulting solid was then filtered off and washed with toluene $(3 \times 20 \mathrm{~mL})$. The supported phenyl group was then sulfonated by refluxing in 1,2dichloroethane $(60 \mathrm{~mL})$ the functionalized material with cholorosulfonic acid $(10 \mathrm{~mL}, 150 \mathrm{mmol})$ under stirring for 4 hours. The solid was then recovered by filtration and washed with 1,2-dichloroethane $(3 \times 20 \mathrm{~mL})$, acetone $(3 \times 20 \mathrm{~mL})$ and water $(3 \times 50 \mathrm{~mL})$ to deliver the title com- 
pound. Acidity has been measured via the titration method [35] $\left(0.65 \mathrm{mmol} \mathrm{H}^{+} / \mathrm{g}\right)$.

$\mathrm{SiO}_{2}-\left(\mathrm{CH}_{2}\right)_{3}-\mathbf{O}-\mathrm{C}_{6} \mathrm{H}_{4}-\mathrm{SO}_{3} \mathrm{H}$ : A mixture of amorphous silica gel $(2.0 \mathrm{~g})$ and bromopropyltrimethoxysilane $(0.76 \mathrm{~mL}$, $4.0 \mathrm{mmol})$ was refluxed in toluene $(80 \mathrm{~mL})$ under stirring for 24 hours. The resulting silica supported 3-bromopropane was recovered by filtration and washed with toluene $(3 \times 50 \mathrm{~mL})$. A mixture of this material $(2.0 \mathrm{~g})$ and sodium phenoxide $(0.6 \mathrm{~g}$, $6.0 \mathrm{mmol})$ in DMF $(100 \mathrm{~mL})$ was then heated at $100^{\circ} \mathrm{C}$ under stirring for 24 hours. Afterwards, the material was filtered, washed with DMF $(3 \times 20 \mathrm{~mL})$ and acetone $(3 \times 20 \mathrm{~mL})$. The resulting solid material $(2.0 \mathrm{~g})$ and chlorosulfonic acid $(4 \mathrm{~mL}$, $60 \mathrm{mmol}$ ) were eventually stirred in refluxing 1,2-dichloroethane $(60 \mathrm{~mL})$ under stirring for 4 hours. The catalyst was then recovered by filtration and washed with 1,2-dichloroethane $(3 \times 20 \mathrm{~mL})$, acetone $(3 \times 20 \mathrm{~mL})$ and water $(3 \times 50 \mathrm{~mL})$. Acidity has been measured via titration method [35] (0.73 $\mathrm{mmol} \mathrm{H}^{+} / \mathrm{g}$ ).

\section{Esterification reaction}

Levulinic acid, pentanol and the heterogeneous catalyst were stirred for 24 hours in a batch reactor under air. The acid/ alcohol ratio, the reaction temperature and the amount of the catalyst were modified as described in the previous section. In all cases, the solid catalyst was eventually recovered by filtration and the reaction mixture was analysed by high resolution capillary GC with a fused silica capillary column SE52 (5\% phenyl, 95\% methyl polysiloxane, $30 \mathrm{~m} \times 25 \mathrm{~mm}$ ). The products were isolated by flash chromatography on silica gel (eluent $=$ hexane/ethyl acetate) and characterised by multinuclear NMR.

\section{Supporting Information}

\section{Supporting Information File 1}

Experimental part and NMR spectra of products.

[http://www.beilstein-journals.org/bjoc/content/ supplementary/1860-5397-12-207-S1.pdf]

\section{References}

1. Gallezot, P. Chem. Soc. Rev. 2012, 41, 1538-1558. doi:10.1039/C1CS15147A

2. McKendry, P. Bioresour. Technol. 2002, 83, 37-46. doi:10.1016/S0960-8524(01)00118-3

3. Beerthuis, R.; Rothenberg, G.; Shiju, N. R. Green Chem. 2015, 17, 1341-1361. doi:10.1039/C4GC02076F

4. Climent, M. J.; Corma, A.; Iborra, S. Green Chem. 2014, 16, 516-547. doi:10.1039/c3gc41492b

5. Strassberger, Z.; Tanase, S.; Rothenberg, G. Eur. J. Org. Chem. 2011, 5246-5249. doi:10.1002/ejoc.201101015
6. Van de Vyver, S.; Peng, L.; Geboers, J.; Schepers, H.; de Clippel, F.; Gommes, C. J.; Goderis, B.; Jacobs, P. A.; Sels, B. F. Green Chem. 2010, 12, 1560-1563. doi:10.1039/c0gc00235f

7. Fukuoka, A.; Dhepe, P. L. Angew. Chem., Int. Ed. 2006, 45, 5161-5163. doi:10.1002/anie.200601921

8. Demma Carà, P.; Pagliaro, M.; Elmekawy, A.; Brown, D. R.; Verschuren, P.; Shiju, N. R.; Rothenberg, G. Catal. Sci. Technol. 2013, 3, 2057-2061. doi:10.1039/c3cy20838a

9. Onda, A.; Ochi, T.; Yanagisawa, K. Green Chem. 2008, 10, 1033-1037. doi:10.1039/b808471h

10. Rinaldi, R.; Palkovits, R.; Schueth, F. Angew. Chem., Int. Ed. 2008, 47, 8047-8050. doi:10.1002/anie.200802879

11. Mäki-Arvela, P.; Salmi, T.; Holmbom, B.; Willför, S.; Murzin, D. Y. Chem. Rev. 2011, 111, 5638-5666. doi:10.1021/cr2000042

12. Corma, A.; Iborra, S.; Velty, A. Chem. Rev. 2007, 107, 2411-2502. doi:10.1021/cr050989d

13. Neves, P.; Antunes, M. M.; Russo, P. A.; Abrantes, J. P.; Lima, S.; Fernandes, A.; Pillinger, M.; Rocha, S. M.; Ribeiro, M. F.; Valente, A. A. Green Chem. 2013, 15, 3367-3376. doi:10.1039/c3gc41908h

14. de Souza, R. O. M. A.; Miranda, L. S. M.; Luque, R. Green Chem. 2014, 16, 2386-2405. doi:10.1039/c3gc41885e

15. Berger, R. G. Flavours and Fragrances - Chemistry, Bioprocessing and Sustainability; Springer, 2007. doi:10.1007/978-3-540-49339-6

16. Bozell, J. J.; Moens, L.; Elliott, D. C.; Wang, Y.; Neuenscwander, G. G.; Fitzpatrick, S. W.; Bilski, R. J.; Jarnefeld, J. L. Resour., Conserv. Recycl. 2000, 28, 227-239. doi:10.1016/S0921-3449(99)00047-6

17. Yan, K.; Jarvis, C.; Gu, J.; Yan, Y. Renewable Sustainable Energy Rev. 2015, 51, 986-997. doi:10.1016/j.rser.2015.07.021

18. Demma Carà, P.; Ciriminna, R.; Shiju, N. R.; Rothenberg, G.; Pagliaro, M. ChemSusChem 2014, 7, 835-840. doi:10.1002/cssc.201301027

19. Zhang, J.; Wu, S. B.; Li, B.; Zhang, H. D. ChemCatChem 2012, 4, 1230-1237. doi:10.1002/cctc.201200113

20. Patil, C. R.; Niphadkar, P. S.; Bokade, V. V.; Joshi, P. N. Catal. Commun. 2014, 43, 188-191. doi:10.1016/j.catcom.2013.10.006

21. Nandiwale, K. Y.; Bokade, V. V. Chem. Eng. Technol. 2015, 38, 246-252. doi:10.1002/ceat.201400326

22. Fernandes, D. R.; Rocha, A. S.; Mai, E. F.; Mota, C. J. A.; Teixeira da Silva, V. Appl. Catal., A: Gen. 2012, 425-426, 199-204. doi:10.1016/j.apcata.2012.03.020

23. Bart, H. J.; Reidetschlager, J.; Schatka, K.; Lehmann, A. Ind. Eng. Chem. Res. 1994, 33, 21-25. doi:10.1021/ie00025a004

24. An, S.; Song, D.; Lu, B.; Yang, X.; Guo, Y.-H. Chem. - Eur. J. 2015, 21, 10786-10798. doi:10.1002/chem.201501219

25. Su, F.; Ma, L.; Song, D.; Zhang, X.; Guo, Y. Green Chem. 2013, 15, 885-890. doi:10.1039/c3gc36912a

26. Pasquale, G.; Vázquez, P.; Romanelli, G.; Baronetti, G. Catal. Commun. 2012, 18, 115-120. doi:10.1016/j.catcom.2011.12.004

27. Peng, L.; Lin, L.; Zhang, J.; Shi, J.; Liu, S. Appl. Catal., A 2011, 397, 259-265. doi:10.1016/j.apcata.2011.03.008

28. Grecea, M. L.; Dimian, A. C.; Tanase, S.; Subbiah,, V.; Rothenberg, G. Catal. Sci. Technol. 2012, 2, 1500-1506. doi:10.1039/c2cy00432a

29. Subbiah, V.; van Zwol, P.; Dimian, A. C.; Gitis, V.; Rothenberg, G. Top. Catal. 2014, 57, 1545-1549. doi:10.1007/s11244-014-0337-x

30. Dimian, A. C.; Rothenberg, G. Catal. Sci. Technol. 2016, 6, 6097-6108. doi:10.1039/C6CY00426A 
31. Zhou, X.; Li, Z. X.; Zhang, C.; Gao, X. P.; Dai, Y. Z.; Wang, G. Y. J. Mol. Catal. A: Chem. 2016, 417, 71-75.

doi:10.1016/j.molcata.2016.03.006

32. Lima, T. M.; Lima, C. G. S.; Rathi, A. K.; Gawande, M. B.; Tucek, J.; Urquieta-Gonzales, E. A.; Zbořil, L.; Paixão, M. W.; Varma, R. S. Green Chem. 2016, in press. doi:10.1039/C6GC01296E

33. Tejero, M. A.; Ramírez, E.; Fité, C.; Tejero, J.; Cunill, F. Appl. Catal., A 2016, 517, 56-66. doi:10.1016/j.apcata.2016.02.032

34. Melero, J. A.; Morales, G.; Iglesias, J.; Paniagua, M.; Hernández, B.; Penedo, S. Appl. Catal., A 2013, 466, 116-122. doi:10.1016/j.apcata.2013.06.035

35. Corma, A.; Garcia, H. Adv. Synth. Catal. 2006, 348, 1391-1412. doi:10.1002/adsc.200606192

36. Maggi, R.; Bosica, G.; Gherardi, S.; Oro, C.; Sartori, G. Green Chem. 2005, 7, 182-184. doi:10.1039/B416665E

37. Maggi, R.; Chitsaz, S.; Loebbecke, S.; Piscopo, C. G.; Sartori, G.; Schwarzer, M. Green Chem. 2011, 13, 1121-1123. doi:10.1039/c0gc00887g

38. Cañeque, T.; Truscott, F. M.; Rodriguez, R.; Maestri, G.; Malacria, M. Chem. Soc. Rev. 2014, 43, 2916-2926. doi:10.1039/c4cs00023d

39. Badley, R. D.; Ford, W. T. J. Org. Chem. 1989, 54, 5437-5443. doi:10.1021/jo00284a014

40. Kiss, A. A.; Dimian, A. C.; Rothenberg, G. Adv. Synth. Catal. 2006, 348, 75-81. doi:10.1002/adsc.200505160

41. Lempers, H. E. B.; Sheldon, R. A. J. Catal. 1998, 175, 62-69. doi:10.1006/jcat.1998.1979

\section{License and Terms}

This is an Open Access article under the terms of the Creative Commons Attribution License (http://creativecommons.org/licenses/by/4.0), which permits unrestricted use, distribution, and reproduction in any medium, provided the original work is properly cited.

The license is subject to the Beilstein Journal of Organic Chemistry terms and conditions:

(http://www.beilstein-journals.org/bjoc)

The definitive version of this article is the electronic one which can be found at:

$\underline{\text { doi:10.3762/bjoc. } 12.207}$ 